\title{
La verdad del corazón humano. Sobre los fines actuales de la historia oral
}

Alessandro Portelli

1 . bre de 1987), la sesión más apasionante fue la latinoamericana; algo paradójico, ya que fue la única que no se organizó alrededor de convergencias metodológicas o temáticas sobre el argumento central del congreso (mito e historia), sino de convergencias geográficas y lingüísticas.

El congreso parecia estancando en ocasiones. Había una definición demasiado vaga del concepto de "mito" (por no decir también de "historia"), por lo que se oscilaba entre un enfoque antropológico muy sofísticado, difícil de ceñir a la dimensión historiográfica del congreso, y relaciones que llamaban "mitos": cualquier convicción o creencia dotada de fuerte poder de atracción y persuasión. No faltaban, naturalmente. aportaciones valiosas (como siempre y en primer lugar, las italianas; v.g. la ponencia de Luisa Passerini durante la jornada-inaugural). pero era dificil establecer una trama común entre los diferentes problemas y demandas.

Otro problema creo que reside en el ya endémico sentimiento de inferioridad de la "historia oral", que induce a su legitimación constante, casi implorante. ante los historiadores "verdaderos" (por ejemplo, la ponencia inaugural de Francois Bedarida fue desilusionante; sin embargo me explicaron que Bedarida es casi el único historiador "verdadero" que se digna descender hacia nosotros...), demostrando que somos también rigurosos, profesionales o interdisciplinarios (paradójicamente queremos demostrar que también somos historiadores y acéptamos discursos sobre "lo oral" sin que estén relacionados con la historia; cada quien parapetado dentro de su especialidad, tratando de crear la ilusión de un encuentro interdisciplinario). En tal contexto fue interesante encontrar a los latinoamericanos que tal vez ingenuamente, centraban el discurso no tanto en la profesión, los estatutos y el método, sino en las personas, la política y el significado.

La mexicana Eugenia Meyer leyó (acaparando la atención general) una larguísima comunicación titulada Memorias de una prisionera política, que consistía en una pequeña introducción histórico-cronológica, una breve conclusión y el impactante relato de una mujer uruguaya.

El hecho de ser mujer planteaba situaciones diferentes para ellos (los torturadores). Sí, claro, hay torturadores que se sientan en una silla y sientan en sus rodillas a la persona que van a torturar para hacerle picana, por ejemplo, y por lo tanto se hacen picana ellos también. Es decir, hay toda una cuestión sadomasoquista en todo eso que seguramente les produce placer, porque otra explicación no tiene...

Pero todo esto, en realidad, no es lo peor en la vida del penal, lo peor no han sido los trabajos... el ambiente físico del propio penal, ni lo peor es la comida, o las condiciones de sueño; lo peor es todo lo que no se ve, lo peor es el sistema que se ha orquestado para la destrucción de las reclusas... Es 
muy difícil aniquilar a una persona humana sin que redunde negativamente en contra de la dictadura. Por lo tanto, la aniquilación física no es una cosa que se pueda plantear la dictadura gratuitamente. Por lo tanto, deben recurrir a otro tipo de destrucción.

Kathleen Angueira, puertorriqueña, tuvo una intervención más compleja y hasta cierto punto recargada de garantías metodológico-profesionales. Pero las razones eran menos institucionales, más profundas, de sucesos superficiales análogos, porque aquí hasta la bibliografía está contenida en el testimonio. Veremos más adelante el porqué. Esta ponencia también expone un relato que nos hace estremecer.

Fui raptada hace cuatro años, tres hombres me llevaron a un sembradío de caña de azúcar y me violaron... El estupro en sí duró cuatro horas - las más largas de mi vida-. Durante ese lapso perdí el control de mi ser como persona, más concretamente de mi ser físico. Estaba a merced de mis raptores... El miedo y la humillación eran casi inimaginables: traté de esconder la sortija, esperando que renunciaran a violar a una "virgen", que me permitieran conservar los zapatos, única indumentaria que me quedaba para cubrir cualquier parte de mi cuerpo y, al final, cubrir mi desnudez con mis cabellos para poder seguir sintiéndome humana, una persona...

Al volver a casa, encontré una escena desconcertante: estaba llena de personas que, a las tres y media de la mañana, consolaban a mis padres. Recuerdo la angustia de mi madre, sentada, con una fotografia mía en su regazo -el tipo de fotografias que publican anunciando la muerte, el asesinato de alguien-. Me pareció ser el fantasma de la persona que esperaban.

2. "Sentirme persona": dentro de estas historias encontramos tentativas de "aniquilación de la persona humana" y resistencias desesperadas para no convertirse en "fantasmas".

Cuando comenzó a crecer en mí (como en otros) la pasión por la "historia oral", no era con el afán de crear una nueva base para las disciplinas académicas. Dado el trabajo que desempeño, no puedo permitirme ni prejuicios ni ironías con relación a la academia ni con las disciplinas. Pero en cuanto que soy citadino, sé que no todo se restringe a estos confines. Me parecía que la historia oral servía, en primera instancia, para enfrentarme a las palabras, experiencias y personas que, en mi condición de académico, no hubiera podido conocer y tratar con la competencia profesional y científica que poseo o me es necesario adquirir, pero también con esa emoción respetuosa que me provoca el encontrarme frente a personas y no a documentos.

Tal vez porque he tenido el afortunado privilegio de cursar mi carrera universitaria en una disciplina totalmente separada de las historiográficas he podido darme el lujo de enfrentar este trabajo impulsado solamente por el deseo de conocer aspectos de la realidad e intervenir en ella. Me ha ayudado en esto el hecho de que la historia oral atrae también a colegas historiadores de profesión, que tienen (en diversos grados) motivaciones de este tipo, y a diletantes, aficionados y autodidactas; incompetentes, honestos y desinteresados en su afán de conocer mejor la realidad y su significado.

Mitos positivistas, naturalmente. Mi bagaje de estudioso de historias, me permitió darme cuenta de que, más que recopilar la verdad, la realidad, "lo vivido", la materia de la experiencia, lo inmediato del testimonio, compilábamos mediaciones, interpretaciones, representaciones, mistificaciones, memorias, impresiones, errores, mentiras. Sólo palabras: y sobre ellas he escrito mis mejores trabajos. 
La realidad, el significado (¿la "verdad"?) se revelan como utopías inalcanzables si es que no quimeras ilusorias. Y en estos tiempos de destrucción, el solo hablar de realidad puede provocar la burla. Por lo tanto, de la investigación acerca de la acertada reconstrucción de los acontecimientos (recuerden las interminables polémicas sobre la "confiabilidad de las fuentes orales") nos hemos desviado a través de las palabras, de la memoria, de la psicología, hacia "la subjetividad".

Tampoco esta palabra mágica elude la confrontación con la incómoda quimera de la verdad. En la introducción de The Blithedale Romance (1852), Nathaniel Hawthorne explicaba la diferencia entre la novela realista novel y lo que él llama romance, que reside en el hecho de que este último puede estar exento de "La minuciosa fidelidad... del curso probable y usual de la experiencia" pero no puede nunca "desviarse de la verdad del corazón humano". Dejando de lado la terminología del mil ochocientos, yo creo que esto quiere decir que "la subjetividad" ("el corazón humano") no significa "arbitrariedad"; que no todas las subjetividades son equivalentes, intercambiables, definitivamente indiferentes; que una tendencia hacia "la verdad" — nunca única, nunca incontrovertible, casi seguramente inalcanzable, pero siempre so pena de cinismo profesional, irremediablemente deseablees requisito ético antes que profesional, de cualquier historia, incluida la historiografía.

3. El ansia de develarse de la prisionera política uruguaya Ofelia Fernández es metafóricamente afín al ansia de cubrirse de la mujer de Puerto Rico en el momento de la violencia: salvar la "verdad" del propio human heart retomando la palabra y al mismo tiempo manteniendo el control de sí mismo, no ofrendarse indefenso al control de otros. De ahi los métodos especulativos y complementarios de laș dos investigadoras.

Para Eugenia Meyer, la fidelidad a la verdad humana de Ofelia Fernández significa anularse, tamizarse: dar sólo aquel mínimo de información que permite ser comprendida. Hemos polemizado largamente sobre los excesos de ingenuidad en la ideología de la historia oral entendida como medio de difusión a la palabra de los oprimidos y marginados, y no creo que sea adecuado retroceder en este aspecto: la voz de la "fuente" es siempre mediata, está siempre filtrada por el investigador; por más que el investigador quiera ser agente "neutro" y transparente, es imposible, no sólo metodológica y políticamente hablando, sino imposible de hecho, ya que la sola presencia del investigador modifica el testimonio. Pero tampoco es justo considerar este descubrimiento como un talismán que nos impide escuchar a la gente, que nos autoriza a sustituir nuestra voz por la de ellos y a adjudicarnos el derecho a la decisión de lo que significa lo que ellos dicen. En plena cárcel y tortura, aun sintiendo y expresando "desprecio" por los torturadores que buscaban la anulación de su humanidad, Ofelia Fernández no logra olvidarse de la humanidad de los torturadores. Para insultarlos los llama "infelices": "Aquellos hombres... eran terriblemente infelices, desgraciados, miserables pero infelices".* Dialogar con Ofelia Fernández significa para Eugenia Meyer callar, escuchar, repetir (casi como ventrílocuo) con el objetivo de evitar que esta mujer, que no permitió ser rebajada a un simple objeto de los torturadores, y que para seguir siendo humana, no quiso olvidarse de la humanidad de

* En español en el original. 
ellos, sea anulada como persona, convirtiéndose en objeto de investición, elaboración e interpretación.

No es ésta la única forma posible. Yo casi nunca trabajo así: estando acostumbrado a componer y descomponer los relatos de acuerdo a la práctica estructuralista y formalista (condimentada con algunos elementos hermenéuticos y de destrucción), llevo a cabo análisis y mosaicos de integración; por lo tanto no estoy reivindicando el retorno a la simplicidad de nuestros antepasados ni a la palabra popular no contaminada, lo que estoy diciendo es que el análisis, la crítica y la integración se vuelven ejercicios vulgares y vacios si no se encuentran animados a cada instante por el recuerdo del hecho humano con que establecimos contacto al inicio; y que existen, a veces, hechos materiales, palabras tan fuertes, que componer, reconstruir, explicar o mediar, significa reducir, violar. Esto nos recuerda a Eugenia Meyer. Dije que Kathleen Angueira, había enfocado el asunto de otra manera, pero por las mismas razones. El momento más emocionante de tantos congresos de historia oral en los que he participado llegó exactamente cuando, sin que hubiera alteración alguna en el tono de la voz, de manera que nos dimos cuenta de lo que se estaba diciendo, ella dijo: "es necesario formular un marco crítico-teórico que justifique el uso de la experiencia de una mujer como instrumento educativo, y aplicarlo a una situación como la presente en la que la investigadora, el sujeto y el pbjeto sean la misma persona". La mujer de la cual refiere el dramático testimonio, es ella misma; y su argumento, dirigido a demosțrar el valor terapéutico y político del discurso, es la ilación del testimonio.

Solamente en otra ocasión he sentido emociones comparables, a propósito de la relación que se establece entre la verdad de quien la emite y quien la dice como historiador. Maryat Moore, historiadora y sindicalista norteamericana, contó las historias de las mujeres en el ramo de la minería, citando ampliamente las narraciones de una "relatora" excepcional, que posteriormente, agregó también ella sin acentuar: "era mi mejor amiga, y murió enterrada". Tal vez sea sólo un caso - de hecho no lo había considerado- pero en los tres casos se trataba de mujeres ocupándose de historias de mujeres.

Eugenia Meyer se involucra y se expresa por medio del silencio, gracias al cual logra casi desaparecer como investigadora y fundirse con la fuente. La expresión de Maryat Moore es la reivindicación centrada en una relación afectiva; Kathleen Angueira se escinde y finge hablar de sí misma como si fuera otra persona. El tono neutro, científico, académico con el que trata de desmenuzar el relato de una experiencia que no se puede dividir y de la cual es víctima, se transforma en lo contrario de, lo que aparenta: una expresión gélida de furia, con el fin de no volver a ser.humana y perder de nuevo el control.

Pero aún hay más: la competencia profesional llevada hasta la subdeterminación es a su vez parte de una batalla política. Kathleen Angueira trabajaba, desde antes de la agresión, en un centro de ayuda a mujeres violadas. Después de lo ocurrido fue la primera en atreverse a denunciarlo, dando su nombre y apellidos, y a narrarlo, subrayando el valor político y terapéutico de "tomar la palabra". A esas alturas se vio enfrentada a una resistencia imprevista: la de los profesionales de la asistencia, los psicólogos de carrera y sus propios colegas. El mismo hecho de tener un conocimiento directo acerca de lo que estaba narrando, minaba su credibilidad profesional y personal. La "verdad del corazón humano" de una mujer violada, no era compatible con la 
verdad institucional. La jerga psicológica de la relación le sirve para cubrirse ante la confrontación, igual que los cabellos frente a los violadores.

4. También nosotros nos hemos afanado en cubrirnos. La lucha para otorgar a quien usa las fuentes orales, el derecho de ciudadanía en la república de la historiografía, ha sido larga y extenuante, ha tenido algunas victorias limitadas, que nos dejan un amargo sabor de boca. Algunas universidades han dado cabida a este tipo de investigación, en algunos casos aislados han sido consideradas experiencias didácticas oficiales. Muchos organismos locales o Institutos Históricos de la Resistencia han creado archivos, algunas veces sin saber muy bien qué hacer con ellos. Grupos como el Movimiento de Cooperación Educativa han insistido en la importancia de las fuentes orales. Las revistas científicas publican libros y resúmenes de congresos sin hostilidad premeditada. Sin embargo continúo encontrando investigadores jóvenes, excelentes estudiosos, que consideran adecuado el mantener minuciosamente ocultas sus fuentes orales al optar por un doctorado en investigación, oral historians brillantes que suponen ser más dignos, respetables y profesionales, si subordinan sus fuentes orales a un cuadro conceptual ajeno a ellas. La inmensa mayoría de los libros de historia que se publican en nuestro país, no recurren sistemáticamente a las fuentes orales (en general simplemente no las usan). Y los artículos de Eugenia Meyer y Kathleen Angueira no serán traducidos por revistas científicas famosas, sino (de la manera más completa posible), por un periódico híbrido llamado I Giorni Cantati.

El nacimiento un poco controvertido de una Sociedad Italiana de la Historia Oral es una maravillosa noticia, aunque haya sido necesario más de un año para darle forma; signo, no de pluralismo, sino de debilidad. Creo que es necesario tomar en cuenta entre sus objetivos primarios el reconocimiento profesional, el acceso a las fuentes, la definición de las técnicas de recolección, archivo, clasificación del material; que enfrente los problemas de deontología profesional, que insista en un pluralismo metodológico, académico (y extra académico) y político más amplio, que se oponga a considerar a las fuentes orales como un universo aparte, sin sacrificat lo específico y la autonomía. No se le puede exigir todo a una asociación profesional (aunque muchos de los integrantes no sean profesionistas). Espero que esta posición no se considere negativa, si digo que todo es mucho pedir, pero hay cosas (para mí) más importantes, que se quedan fuera y sin las cuales lo demás (para mí) tiene poco sentido. Después de todo métodos, técnicas, instrumentos;-estatutos profesionales son herramientas (medios), el fin es la volátil, cambiante y subjetiva "verdad".

Cuando yo (como otros) comencé a trabajar con las fuentes orales no pensaba enriquecer el instrumental de lo histórico con otros métodos y documentos que mediante un uso apropiado engrosaran quizás las notas marginales. Mi idea era sacudir los conceptos de propiedad (del lenguaje) y de documento. El hecho de reconocer que la palabra es universalmente difusa, y que esto se utilice en contra de los seres humanos, me parecía un factor de tal envergadura que removería todas nuestras opiniones: dentro de la literatura me interesaba hacer irrumpir la oralidad para encadenar las verdades del texto y del "credo" de los textos consagrados, y en la historia me parecía que hubiéramos podido sacudir la presunción de la certeza y exclusividad del discurso 
de las fuentes oficiales, de todas las fuentes. Con esto, no me interesaba simplemente derrumbar las jerarquías, poner un canon en lugar de otro (después de todo, aquí cito a un autor que no puede ser más canónico, Hawthorne), sino abolir la propiedad institucional de la verdad.

Esto no tuvo éxito, no a todos los historiadores orales les interesaba un proyecto semejante, otros prefirieron fingir que el problema no había sido expuesto. Inevitablemente, nos contentamos con mucho menos y nos mediatizamos en una ciudadanía de segunda, una especie de nacionalización siempre sujeta a revisión y revocación, que genera una pulsión de asimilación del inmigrante ansioso, una transacción de nuestro pátrimonio de divergencia.

Pienso en el "68". La historia de los jóvenes hecha por Panorama, como se la conoce: las repetidas evocaciones hacen manifiesta la ausencia de los historiadores, quienes deberían tener doble razón para hablar. Por un lado porque nuestro método de trabajo podría arrebatar el monopolio de la memoria a los evocadores oficiales, haciendo hablar a miles de personas, muchachas y muchachos, que hicieron de aquel año un asunto extraordinariamente colectivo, un intercambio de tantas historias personales iniciadas antes, continuadas después. Por otro lado, porque no obstante la diversidad y las remembranzas, el 68 es también una de nuestras fechas de nacimiento: estábamos nosotros, ideológica más que físicamente. Yo por ejemplo, no participé en el 68, no soy un reducto; de ahí tomamos las ideas de los protagonistas de la cultura y del significado de la investigación que nos encaminó hacia las fuentes orales. Renunciar a decir otra cosa del 68 significa perder una extraordinaria oportunidad metodológica para verificar, dentro de nuestra propia memoria, y sustraernos de nuestra propia verdad antes que afrontarla, tal vez cambiarla, pero decir que es nuestra.

Naturalmente, retomar el disçurso de una historia que nos pertenece y para cuyo estudio estamos científicamente capacitados, significa llevar a cabo una batalla política, y no todos quieren hacerlo. Pero sospecho que si no recomenzamos a dar batallas de este tipo, si no molestamos a los manipuladores que nos asignan asientos en los camiones, podremos mejorar nuestra profesión, pero no seremos más que profesionistas mediocres. 